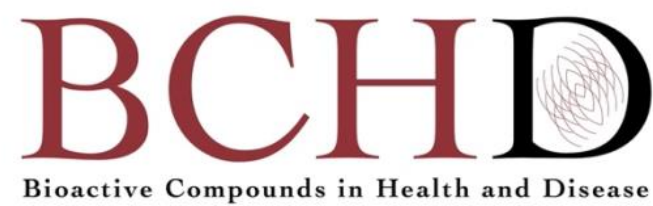

\title{
Effect of preoperative feeding with germinated brown rice supplement on clinical outcome of orthopaedic and gastrointestinal surgery patients
}

\author{
Pooja Thacker $^{1 *}$, Subhadra Mandalika², Rahul Shah ${ }^{3}$, Nilesh Doctor $^{4}$
}

${ }^{1}$ Department of Nutrition and Dietetics, Bhatia Hospital., Mumbai, India; ${ }^{2}$ Department of Food, Nutrition and Dietetics, College of Home Science Nirmala Niketan, Mumbai, India; ${ }^{3}$ Department of Orthopaedics, Bhatia Hospital., Mumbai, India; ${ }^{4}$ Department of Gastroenterology and Hepatobiliary, Bhatia Hospital., Mumbai, India

*Corresponding Author: Pooja Thacker, PhD scholar, College of Home Science Nirmala Niketan, HOD Dietetics, Bhatia Hospital, Mumbai, India

Submission Date: April 6 $6^{\text {th }}$ 2021; Acceptance Date: June $1^{\text {st }}, 2021$; Publication Date: July $16^{\text {th }}, 2021$

Please cite this article as: Thacker P., Mandalika S., Shah R., Doctor N. Effect of preoperative feeding with germinated brown rice supplement on clinical outcome of orthopaedic and gastrointestinal surgery patients. Bioactive Compounds in Health and Disease 2021; 4(7): 149-166. DOI: 10.31989/bchd.v4i7.799

\section{ABSTRACT}

Background: Malnutrition prior to surgery can lead to inflammation, increased length of hospital stay, bed sores, muscle weakness, poor quality of life and mortality post-surgery in patients. Therefore, preoperative drinks that have been enriched with vitamins, easily digestible carbohydrates and amino acids have been necessitated by ESPEN. Health benefits of brown rice, which is a good source of phytonutrients like GABA, Ferulic acid Oryzanol and B-complex, BCAA and maltodextrin, have been well researched.

Methods: In the present study, a nutritious product was developed using germinated brown rice, salt and micronutrient mix (GBR Mix), analysed quantitatively (Proximate composition) and qualitatively (Phytochemicals). Major orthopaedic and gastrointestinal surgical patients in the age group of 40-65 years $(n=124)$ were supplemented with GBR Mix in bouts of 3 meals (20gms x 3meals) namely lunch, mid-evening and bedtime time snack, $8 \mathrm{hrs}$ prior to surgery unlike other patients who fasted for 12-16 hours prior to surgery. They were assessed for nutritional status, Serum Albumin, inflammatory markers (CRP and WBC), post-surgery complications and length of hospital stay.

Results: Supplementation was found to improve blood sugar $(p<0.05)$ in gastroenterology patients, reduce inflammatory markers like CRP $(p=0.053)$ and WBC $(p<0.001)$, reduced nausea and vomiting, improved food and fluid intake post-surgery in the patients. Additionally, length of hospital stay was also reduced $(p=0.001)$. 
Conclusion: Thus, germinated brown rice could be recommended as an economical nutritious and antiinflammatory pre surgery feed.

Keywords: GBR, LOS, MUST, SGA, CRP, Micronutrient Mix

CFFC 2021. This is an Open Access article distributed under the terms of the Creative Commons Attribution 4.0 License (http://creativecommons.org/licenses/by/4.0)

\section{INTRODUCTION}

Trauma is a neuro-hormonal stress that induces changes in the anabolic and catabolic functions within the body. This has many effects, including increased proinflammatory cytokines, catabolism and activation of sympatho-adrenal system. The regulation of balance between anabolism and catabolism is hampered mainly by insulin resistance which is directly proportional to the surgical insult $[1,2]$. Insulin resistance develops due to preoperative reduced energy intake due to malnutrition which leads to multiple metabolic effects like reduced hepatic and peripheral insulin response, negative nitrogen balance, muscle catabolism, carbohydrate oxidation and reduced muscle strength as insulin shares the same signalling pathway $[3,4]$. Studies have documented malnutrition and energy deficit as serious problems in surgical patients, especially in major abdominal surgeries which lead to increased infections and length of hospital stay (LOS) $[5,6]$. Malnutrition due to anorexia and vomiting results in poor food intake which leads to approximately more than $10 \%$ weight loss over a period of 6 months in patients undergoing major surgery. Therefore, weight stabilization is an important component for such patients especially before and after surgery $[7,8]$.

Traditionally, overnight fasting was followed as a regime prior to surgery, but various studies have shown that prolonged fasting does not reduce gastric contents, rather increases discomfort. Various research studies have proven pre-operative carbohydrate loading successful in gastrointestinal (GI) surgeries [9] hip replacements [10], thyroidectomy [11] and onco- surgeries [12] by reducing episodes of nausea, vomiting, insulin resistance, thirst, LOS and mortality. Combination of maltodextrin and sucrose in nutritional supplements aid in absorption by GLUT 4 carrier (Mopette et al, 2016) [13]. Further, researchers have also demonstrated beneficial use of maltodextrin from various sources like corn starch, pea starch along with whey. In addition, the combination of maltodextrin and other nutrients such as protein, vitamins and minerals was also shown to reduce alpha- TNF, insulin resistance and risk of brochoaspiration in cholecystectomy surgery patients [14].

Various international associations like ESPEN, ASPEN, and Enhanced Recovery after Surgery (ERAS) have recommended shortening the duration of preoperative fasting to enhance the recovery of surgery. Carbohydrate ingestion (loading) prior to surgery was recommended to maximize glycogen storage in the body as a source of energy and reduce degradation of tissues and insulin resistance, thereby combatting surgery induced inflammation [15].

Pre germinated brown rice demonstrated therapeutic benefits of lowering blood pressure, post prandial sugars [17], homocysteine levels [18] and boasting immunity due to its phyto-nutrient properties [19]. Also, germinated brown rice (GBR) is 
a rich source of vitamin $E$, niacin, magnesium; thiamine, folic acid, zinc, inositol, gamma oryzanol and Gamma-aminobutyric acid (GABA) content [16] Watanabe et al. (2016) described GBR rice as 'medical rice' as the germinated brown rice had low glycaemic index of about 55 making it not only diabetic friendly but also renal friendly as they prevented urine protein loss and hyperkalaemia [20].

Therefore, the present study was conducted to evaluate the effect of preoperative feeding of patients undergoing surgery with brown rice supplement on postoperative outcome and length of hospital stay.

\section{MATERIALS AND METHODS}

The study was conducted into two phases- Product development and intervention trial.

PHASE 1 - PRODUCT DEVELOPMENT

A. Germination of Sonamasuri brown rice Sonamasuri brown rice was germinated following the procedure documented by Swati. B. Patil, (2012) [21]. Additionally, 10 gms of green tea leaves (taken in a muslin cloth pouch) were added to brown rice while soaking in order to control development of foul smell. The pouch was discarded post germination. The germinated Sonamasuri brown rice (GBR) was dehydrated and analysed for Maltodextrin content using spectrophotometry.

B. Estimation of Maltodextrins in GBR by Spectrophotometric method: Duplicate samples of GBR were taken, gelatinized, saccharified and analysed for maltodextrin content as described below.

a. Gelatinization and Saccharification: $100 \mathrm{ml}$ distilled water was added to $5 \mathrm{gm}$ of finely powdered GBR in a flask. Then the flasks were autoclaved at 15 psig for 30 minutes. After that, $40 \mathrm{ml} 6(\mathrm{~N}) \mathrm{HCl}$ was added in flask and inversion was carried out at $67^{\circ} \mathrm{C}$ for 45 minutes. Neutralization of $\mathrm{pH}$ of the hydrolysed mass was done by sodium hydroxide solution $(40 \% \mathrm{w} / \mathrm{v})$ and then volume was make up to $200 \mathrm{ml}$ in the flask. The sample was then taken for assay of malto-dextrin.

b. Estimation of Maltodextrin content: $0.2,0.4,0.6,0.8,1 \mathrm{ml}$ of the standard solution and $1 \mathrm{ml}$ of sample solution was pipetted out in test tubes. $2 \mathrm{~mL}$ of Dinitrosalicylic acid reagent (DNS reagents) was added in each of the test tubes. This was then heated in a boiling water bath for 5 minutes. $1 \mathrm{ml}$ of $40 \%$ Rochelle salt solution was added to each of the test tubes. The contents were cooled. The volume was made up to $11 \mathrm{ml}$ in each of the test tube. The absorbance of the solution was measured at $560 \mathrm{~nm}$ on spectrophotometer. A Standard curve was prepared with $0-2 \mathrm{mg}$ dextrose solutions. From the standard Dextrose curve, the value of maltodextrin was calculated.

\section{Development of GBR nutritional mix:}

a. GBR nutritional mix was prepared by adding micronutrient pre mix and salt to the germinated Sonamasuri brown rice (GBR) to improve its nutritional quality and shelf life (Table 
Table 1. Ingredients of GBR nutritional mix

\begin{tabular}{|cc|}
\hline Ingredients & Amount \\
\hline Germinated brown rice(GBR) powder & $100.0 \mathrm{~g}$ \\
\hline Salt & $100 \mathrm{mg}$ \\
\hline Vitamin-mineral premix & $200 \mathrm{mg}$ \\
\hline Total yield & $100.3 \mathrm{~g}$ \\
\hline
\end{tabular}

Table 2. Percent micronutrient composition of nutritional pre-mix

\begin{tabular}{|c|c|c|}
\hline Sr.no & Micronutrients & Amount/100gm \\
\hline 1. & Vitamin A (palmitate) & $4800 \mathrm{mcg}$ \\
\hline 2. & $\begin{array}{l}\text { Vitamin B1 (thiamine } \\
\text { mononitrate) }\end{array}$ & $1.4 \mathrm{mg}$ \\
\hline 3. & Vitamin B2 (Riboflavin) & $1.6 \mathrm{mg}$ \\
\hline 4. & Vitamin B3 (Nicotinamide) & $18 \mathrm{mg}$ \\
\hline 5. & $\begin{array}{l}\text { Vitamin B5 (Calcium D } \\
\text { pantothnate) }\end{array}$ & $5 \mathrm{mg}$ \\
\hline 6. & $\begin{array}{l}\text { Vitamin B6 (pyridoxine } \\
\text { hydrochloride) }\end{array}$ & $2 \mathrm{mg}$ \\
\hline 7. & Vitamin B9 (folic acid) & $200 \mathrm{mcg}$ \\
\hline 8. & Vitamin C (ascorbic acid) & $40 \mathrm{mg}$ \\
\hline 9. & $\begin{array}{l}\text { Zinc (Zinc sulphate } \\
\text { monohydrate) }\end{array}$ & $12 \mathrm{mg}$ \\
\hline 10. & Selenium (sodium selenite) & $40 \mathrm{mg}$ \\
\hline
\end{tabular}

\section{Nutritional analysis of GBR Nutritional mix:}

Methods followed for quantitative and qualitative analysis of the GBR are described below.

a. Moisture content: Water content of the sample is reduced by heating in hot air oven. $10 \mathrm{~g}$ of sample was take in clean, dry and pre weighted petri dish. The petri dish was kept in a hot air oven at $105 \pm 5$ degree Celsius and cooled in a desiccator. The process of heating and cooling was repeated until constant weight was achieved. Moisture content was calculated as follows:

\section{$\%$ Moisture $=\quad$ Loss in weight of sample $\quad x \quad 100$ Weight of sample before drying}

\section{b. Proximate composition}

Protein (Macro kjeldahl method): The method determines total nitrogen in the sample. The crude protein content was then determined by using a conversion factor 6.25 (equivalent to $0.16 \mathrm{~g}$ of Nitrogen /g of protein). This method involves three steps. 
Decomposition involves digesting organic matter in the presence of acidic medium of sulphuric acid and catalyst mixture. Digestion converts nitrogen in the food into ammonia and organic matter to carbon dioxide and water. In the acidic solution, ammonia remains as ammonium sulphate.

Distillation: The digested sample is made alkaline by adding sodium hydroxide, which converts ammonium sulphate into ammonia. On heating ammonia is distilled out and trapped in boric acid solution to form ammonium borate.

Titration: Nitrogen content is then estimated by titration of ammonium borate against standard solution of sulphuric acid in the presence of methyl red and bromocresol green indicator to determine the end point of the reaction which is light pink in colour.

A moisture free sample (500mg) was weighed and transferred to the digestion tube. $5 \mathrm{ml}$ of conc. sulphuric acid and a pinch of digestion mixture (CuSO4 1mg, K2SO4 5g and sodium selenite 1g) were added to it. The contents were digested at 350 Celsius until the solution became very clear. The solution was then distilled in kjeldal distillation unit for 7 mins. Ammonia liberated during distillation was trapped in a flask containing $20 \mathrm{ml}$ of $4 \%$ boric acid solution and kjeldal indicator (methyl red 30gm, bromocresol green $20 \mathrm{mg}$ mixed in $40 \mathrm{ml}$ 90\%ethanol). The boric acid was then back titrated against standard sulphuric acid solution $(0.06 \mathrm{~N})$. Ammonium sulphate was used as standard.

$\%$ nitrogen and \% protein were calculated as follows: $\%$ Nitrogen $=14 \times$ Normality of acid titre value $\times 100$ Weight of sample (g) $\%$ Protein $=\%$ Nitrogen $\times 6.25$
Estimation of total Fat using Soxhlet's method (AOAC, 2000)

Principle: Ether extraction of fat is carried out in the soxhlet's extraction apparatus. Ether is volatilized after dissolving a portion of the fat from food sample and discharging it into the extraction flask. Volatized ether is condensed and allowed to act food sample, this stepping process being automatically operated and the fat continuously extracted until the extraction is completed. The fat content is determined by weighing the extraction flask after complete evaporation of solvent.

Procedure: Pre-weighed and moisture free sample (10gm) was taken is cellulose extraction thimble (25mmx80mm, Whatman). The thimble was placed in soxhlet's apparatus and the sample was extracted under reflux for $16 \mathrm{hrs}$. Petroleum ether was used as a solvent for fat extraction. After extraction the petroleum ether in the flask was evaporated in rotary vacuum solvent evaporator system. The flask with the residue was then flushed with nitrogen, evaporated to dryness and weighed.

\%Fat was calculated as follows:

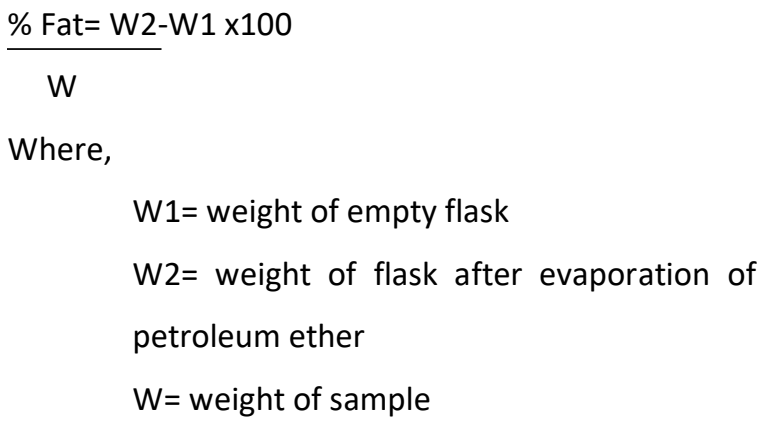

Carbohydrate (difference method): The carbohydrate content of the sample was determined by difference, i.e. by subtracting from 100 the sum of the values (per $100 \mathrm{~g}$ ) for moisture, ash, protein and fat. 
Identification of micronutrients and phytonutrients using HPLC

Method: $1 \mathrm{mg}$ of sample was dissolved in $1.5 \mathrm{ml}$ of Water and kept on hot water bath at 50 degrees Celsius for 1 hour. Solution was vortexed for 30 minutes and centrifuged. Supernatant was collected and filtered through $0.22 \mu \mathrm{m}$ and injected into LCM/MS (AgilantZorbaxEclise XDBC18 $2.1 \times 150 \mathrm{~mm}, 5 \mathrm{um})$ to get a detailed report on nutrients of the sample. HPLC technique was used for qualitative analysis of the product to identify the phytochemicals.

\section{PHASE -2 INTERVENTION TRIAL}

Study population: A total of one hundred and twenty patients $(N=124)$ in the age group of 40 to 65 years (both males and females) undergoing gastrointestinal surgeries $(n=64)$ (Whipple's, pancreatectomy, hepaticojejunostomy and gastrojejunostomy) and orthopaedic surgeries ( $n=64$ ) (hip, knee, spine, femur and shoulder) were selected from Bhatia Hospital, Mumbai, India using purposive sampling technique. A total of four patients were excluded from the gastrointestinal (GI) group including three patients who developed sepsis and one patient died prior to the beginning of the study. Thus the final sample size of $\mathrm{Gl}$ patients was $60(n=60)$. Each group was further subdivided into control and experimental groups.ie 32 each in orthopaedic group and 30 each in gastrointestinal group of patients.

\section{Inclusion criteria}

1. Body Mass Index (BMI) below $30 \mathrm{~kg} / \mathrm{m}^{2}$

2. Patients who were willing to participate in the intervention trial and consume the supplement

\section{Exclusion criteria}

1. Patients on oral hypoglycemic agents

2. Patient suffering from renal/hepatic/septic/psychiatric diseases/gastric insufficiency

3. Pregnant women

Ethics clearance: The study was approved by The Bhatia Hospital Medical Research Society Ethics Committee (Number- ECR-388/Inst/MH/2013) and a written consent letter was obtained from all participants with approved voluntary withdrawal. The patients in each surgery category were further divided into control and intervention groups.

Data collection prior to surgery: Investigator has collected anthropometrical data from all the participants pre surgery using standardized methods described below.

A. Anthropometrical measurements: Following anthropometrical measurements of the participants were recorded early in the morning after passing first urine and with minimal clothes.

- Height -Standing height was measured by keeping the should, buttock and heel touching the wall Mounted stadiometer. The face was kept at 60 degrees and feet without shoes. The nearest measurement to $0.1 \mathrm{~cm}$ was considered.

- Weight - The weight of the patient was recorded to the nearest to $0.5 \mathrm{~kg}$ was recorded (Tanita weighing scale RD 953).

- Body Mass Index (BMI) - It was calculated using the formula- weight $(\mathrm{kg}) /$ height 2 (meter)

- Mid Upper Arm Circumference (MUAC) The superior edge of the scapula to the triceps and the mid portion of the arm was marked. The hands were left free and from the midpoint marked the measurement around the arm was taken without compressing the skin using flexible anthropometric tape. 
B. Biochemical parameters: Blood samples were collected from the participants in EDTA tubes by venepuncture. Plasma was subsequently separated and frozen to-20degree Celsius within 1 hour of collection of sample in the Laboratory. Various parameters like CBC, albumin, electrolyte and fasting blood sugar were assessed using autoanalyzer.

\section{Assessment of nutritional status and Dietary}

Nutrient intake: Nutritional assessment of the participants was carried out pre surgery using Malnutrition Universal Screening Tool (MUST) for GI patients and Subjective Global Assessment Tools (SGA) for orthopaedic patients. Through these tools, information on the history of weight loss, gastrointestinal disturbances like frequency of vomiting and diarrhoea, and changes made in the consistency of diet (if any) was collected. Based on the data collected, patients were graded for their nutritional status. Dietary intake of the patients was recorded using 24-hour diet recall method.

\section{Intervention Protocol}

- Control group: The control group was provided with standard hospital diet supplying 1200 kcals and was kept NBM for 16 hours prior to surgery.

- Intervention group: Sixty grams of the supplement (GBR Nutritional mix) providing 300 calories was administered to the experimental group in three portions thrice a day i.e. 20 grams in lunch, $20 \mathrm{gms}$ at midevening and 20 grams $3 \mathrm{hrs}$ post dinner which was 8 hours prior to surgery followed by NBM (Nil by Mouth). Hospital diet (1200 Calories) and supplement (300 calories) together contributed to a total of $1500 \mathrm{kcals}$ and $50 \mathrm{gm}$ of protein for the intervention groups.
Data collection Post-surgery: Following data were collected from all the participants

A. Biochemical parameters: Blood samples were collected by venepuncture in EDTA tubes. Plasma was subsequently separated and frozen to -20 degrees Celsius within 1 hour of collection of sample in lab. Various parameters like $\mathrm{CBC}$, electrolyte and fasting blood sugar were also assessed using autoanalyzer.

B. Dietary strategy:

Orthopaedic patients were provided diet within $3-5$ hours post-surgery which was progressively modified from liquid to soft to full diet. A 24-hour diet recall of patients was recorded for the subsequent 3 days postsurgery.

Gastroenterology patients- The mean nutritional intake (calories and protein) of the participants was calculated on postsurgery days (POD 7 to 12 ). This is because on the first day post-surgery (POD-1) all the patients were kept NBM and on Total parental nutrition (TPN). From POD -2 Jejunostomy feeds of 500kcals were initiated that were stepped up to $1500 \mathrm{kcal}$ by POD-5. A clear liquid diet was started in small volumes of $30 \mathrm{cc}, 60 \mathrm{cc}, 100 \mathrm{cc}$, and $150 \mathrm{cc}$ from POD-5 to POD-6 and finally on POD-7 soft diet was provided. From the POD-7 to POD-12 nutrient intake of the participants was recorded as patients' intake improved gradually and on counselling patients gradually developed appetite to eat at least $50-75 \%$ of meals just 1-2 days before discharge. 
Statistical analysis: Data were analysed using SPSS version 16.0 and presented as mean and standard deviation. Student $t$ test was applied to analyse the difference in the pre and post-surgery biochemical parameters of inflammatory stress response, nutritional intake and anthropometry of the two groups. Level of significance was established at $5 \%$ level.

\section{RESULTS}

\section{PHASE -1 - PRODUCT DEVELOPMENT}

Sonamasuri brown rice germinated well after 48 hours (Figure 2) and showed good sprout length. No foul odour developed due to the addition of green tea leaves during soaking. The germinated sonamasuri brown rice was analysed for maltodextrin content using spectroscopy and were found to contain 82.18 grams percent of maltodextrin (Table 3).

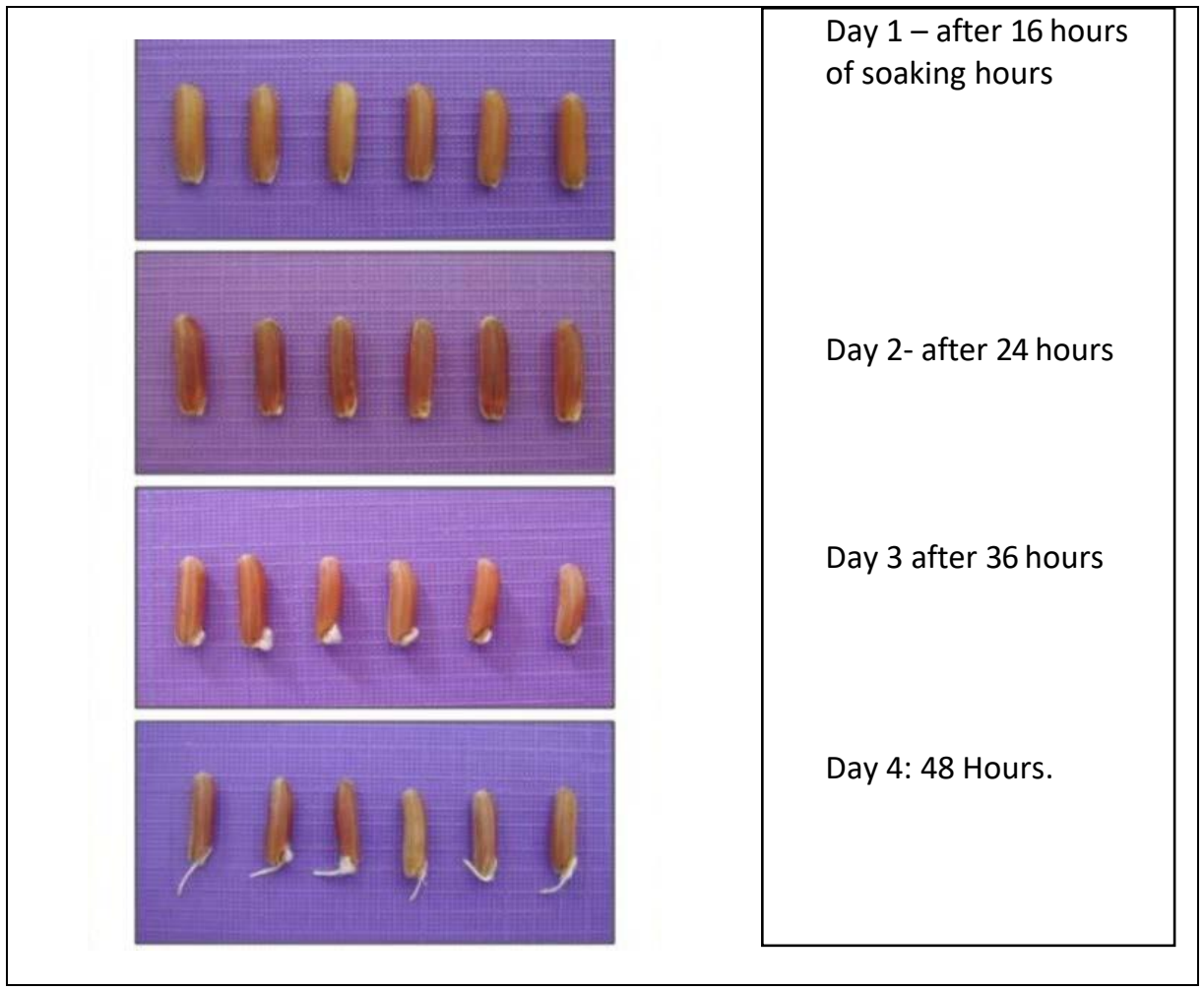

Figure 1. Stages of germination of Sonamasuri brown rice

Table 3. Phytonutrients identified in germinated Sonamasuri rice (qualitative analysis)

\begin{tabular}{|l|l|}
\hline $\begin{array}{l}\text { Deoxythymidine monophosphate } \\
\text { (dTMP) }\end{array}$ & $\begin{array}{l}\text { Dehydro-3-deoxy- } \\
\text { D-arabino-heptonate 7-phosphate (DAHP) }\end{array}$ \\
\hline Epogallaic acid & Sulfadoxine, pyrimidine \\
\hline Cysteine & $\begin{array}{l}\text { 1alpha-hydroxy- } \\
23,24,25,26,27 \text { pentanorvitamin D3--pre form of vit D }\end{array}$ \\
\hline Glycine, Arginine & Serine \\
\hline Glutamic acid & Leucine, Isoleucine and Valine \\
\hline Proline & Tyrosine \\
\hline Aspartic acid & Tryptophan \\
\hline
\end{tabular}


The germinated Sonamasuri rice was powdered and mixed with vitamin mineral pre mix and salt, and quantitatively analysed for moisture, macronutrients and selected micronutrients. Results are shown in Table 4.

Table 4. Percent Nutrient Composition of the GBR supplement and its contribution to RDA of an adult*

\begin{tabular}{|c|c|c|}
\hline Nutrients & Amount & $\%$ of RDA** \\
\hline Moisture (\%) & 7.35 & \\
\hline Ash (\%) & 0.32 & \\
\hline Energy (kcals) & 376.62 & 22 \\
\hline Carbohydrate(gms) & 80 & 26.3 \\
\hline Proteins(gms) & 9 & 25 \\
\hline Fats(gms) & 2.6 & 5.6 \\
\hline Dietary fibre(gms) & 5.2 & 16.6 \\
\hline $\begin{array}{l}\text { Vitamin A(Palmitate } \\
\text { form)mcg }\end{array}$ & 3642 & 364.4 \\
\hline Vitamin C(mgs) & 80.5 & 115.4 \\
\hline Vitamin B1(mgs) & 1.93 & 137.8 \\
\hline Vitamin B2 (mgs)) & 0.32 & 10.5 \\
\hline Vitamin B3(mgs) & 10.75 & 77.5 \\
\hline Vitamin B5(mgs) & 0.08 & 1.6 \\
\hline Vitamin B6(mgs) & 0.225 & 13.75 \\
\hline Vitamin B9 (us) & 16.8 & 8.4 \\
\hline Zinc(gms) & 16 & 94 \\
\hline Selenium(gms) & 0.06 & 150 \\
\hline
\end{tabular}

\section{**Recommended dietary allowance for Indians 2020 by ICMR (Indian council of Medical Research)}

This nutritional mix powder was then used for intervention trial.

\section{PHASE 2- INTERVENTION TRIAL}

\section{Demographic profile of the participants:}

Orthopaedic patients $(n=64)$ : This group included 42.1\% males $(n=27)$ and $57.8 \%$ females $(n=37)$ and were suggested knee replacement /metacarpal/femur/arthroscopies/spine surgeries.

Gastroenterology patients $(n=60)$ : This group comprised of $41.6 \%$ of males $(n=25)$. and $58.3 \%$ of females $(n=35)$ who underwent various gastrointestinal surgeries like Whipple's/hepaticojejunostomy/pancreatectomy/ gastrojejunostomy.

A. Anthropometrical measurements of patients: It was observed that all the patients were malnourished as they had poor BMI and MUAC. Further, it was seen that both male and female patients had significantly poor MUAC $(p<0.075)$. 


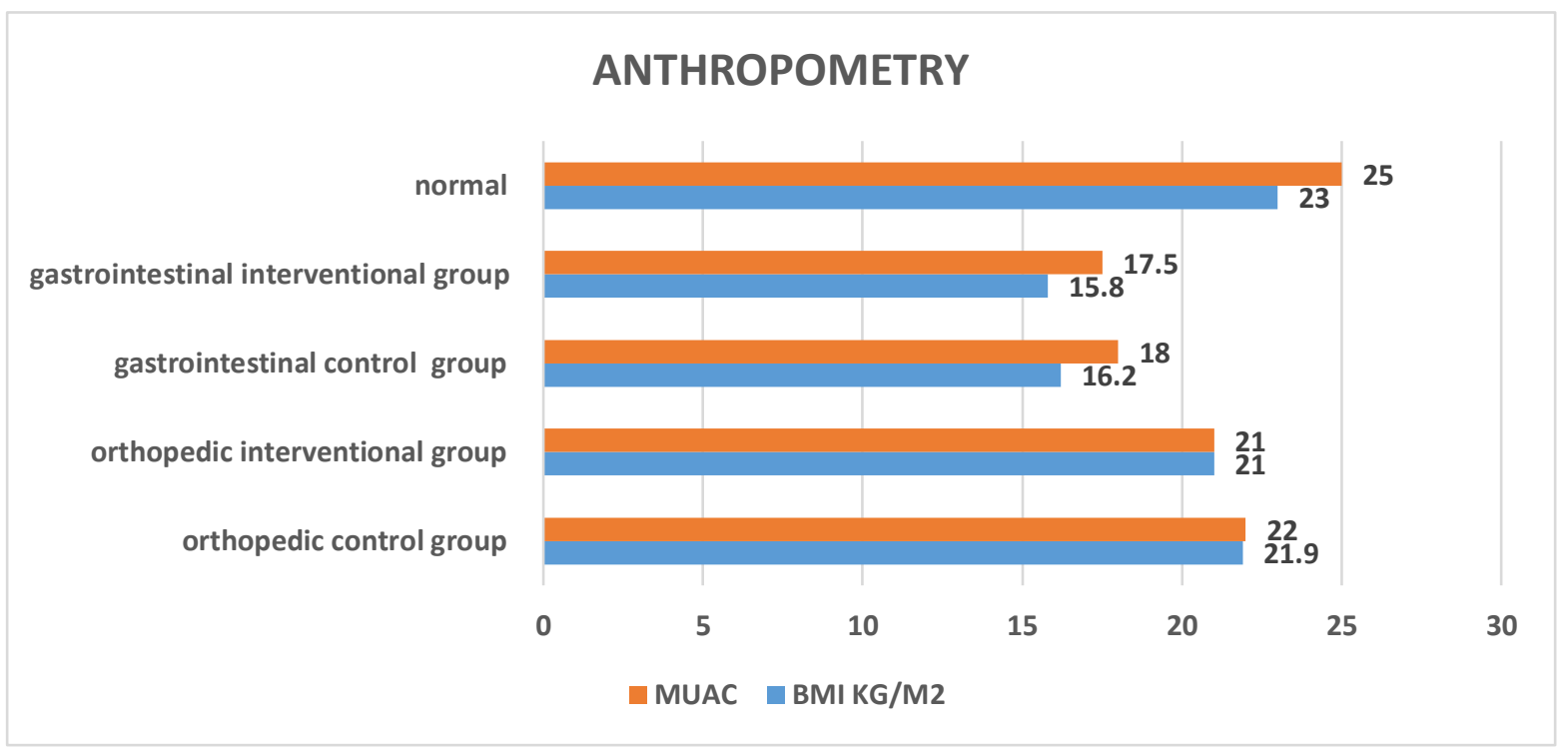

Figure 2. Anthropometric data of participants

** WHO Lancet 2007, Chakraborty D (2011)

In orthopedic patients, there was significant negative correlation of MUAC and BMI with age This clearly indicated that both male and female $(p=0.034)$ indicating increased muscle wasting (Figure 2).

Additionally, in gastrointestinal patients it was observed that females had significantly lower mean MUAC $17.2 \pm 6.3 \mathrm{~cm}$ and BMI $19.7 \pm 4.25 \mathrm{~kg} / \mathrm{m}^{2}$ compared to males [(mean MUAC $19.5 \pm 4.6 \mathrm{~cm}$ and mean BMI $20.3 \pm 3.32 \mathrm{~kg} / \mathrm{m}^{2}$ ] $(p=0.02)$. These results were lower than their respective reference values. patients were malnourished.

\section{B. Biochemical parameters}

Orthopaedic patients: In the present study it was seen that patients with lower $\mathrm{Hb}$ levels and poor albumin status pre-operatively had higher rate of inflammation post-surgery which might have led to an increase in their LOS. Control group of patients had lower serum albumin level ( $2.9 \pm 0.3 \mathrm{~g} / \mathrm{dl})$

\section{BIOCHEMICAL PARAMETER}

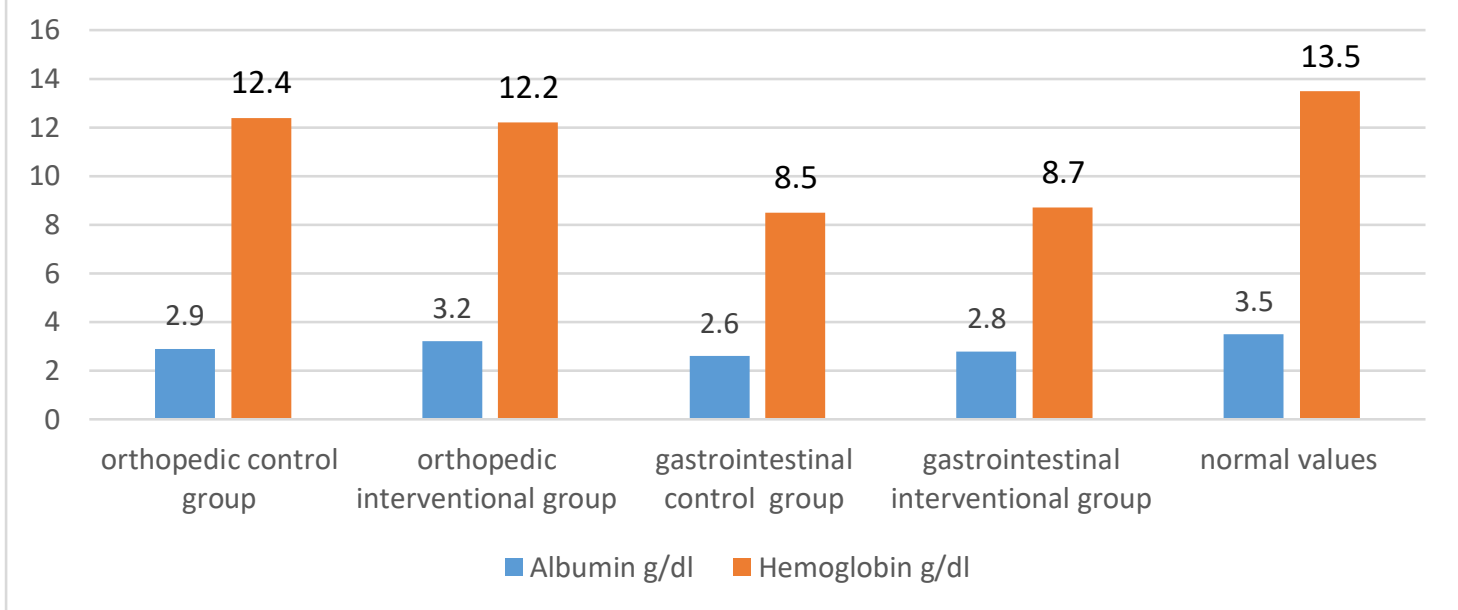

Figure 3. Biochemical parameters of participants- pre surgery 
compared to intervention group $(3.2 \pm 0.2 \mathrm{~g} / \mathrm{dl})$. However, the difference was not significant $(P>0.5)$. A study by Neumaier M etal (2015) showed an association of an increased in serum CRP level with decline in albumin level in 86 orthopaedic patients

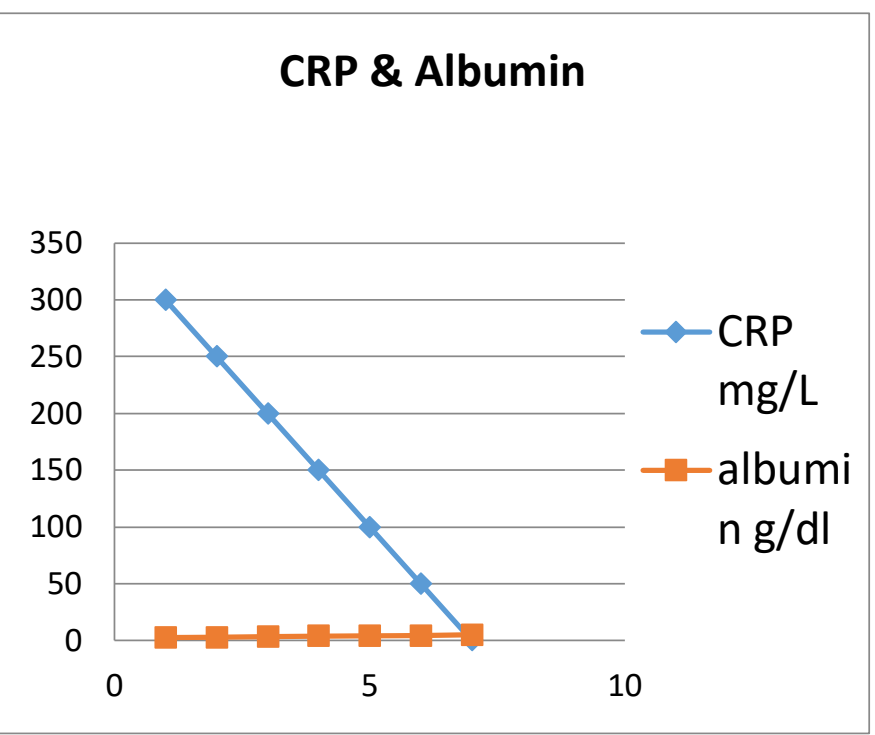

which resulted in an increased risk of osteomyelitis and LOS [22]. Similarly, in the present study a significant negative correlation $(P<0.05)$ was observed between WBC, CRP and albumin (Figure 4).

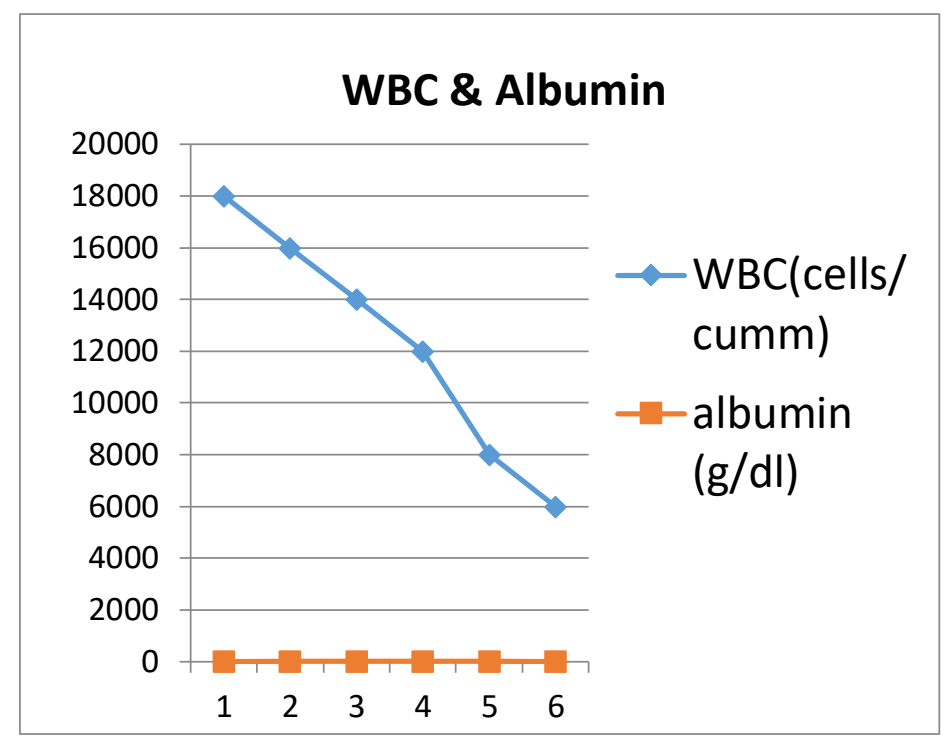

Figure 4. Correlation of CRP, WBC and albumin $(P<0.05)$

Gastroenterology patients: It has been observed that both control and intervention groups of Gastroenterology patients had lower haemoglobin levels which was non-significant $(p=0.79)$ and required blood transfusion. It was noted that $20 \%$ of females and $13 \%$ of males had blood transfusion prior to surgery.

B. Nutritional screening of the participants:
Orthopaedic patients: Nutritional status of orthopaedic patients was conducted using SGA tool. The SGA score of was calculated based on weight, $\mathrm{BMI}$, anthropometry, biochemical parameters and clinical symptoms of orthopaedic patients and the patients were classified based on their level of malnutrition as high risk (23.4\%), medium risk (42.2\%) and low risk (34.3\%) (Figure 5).

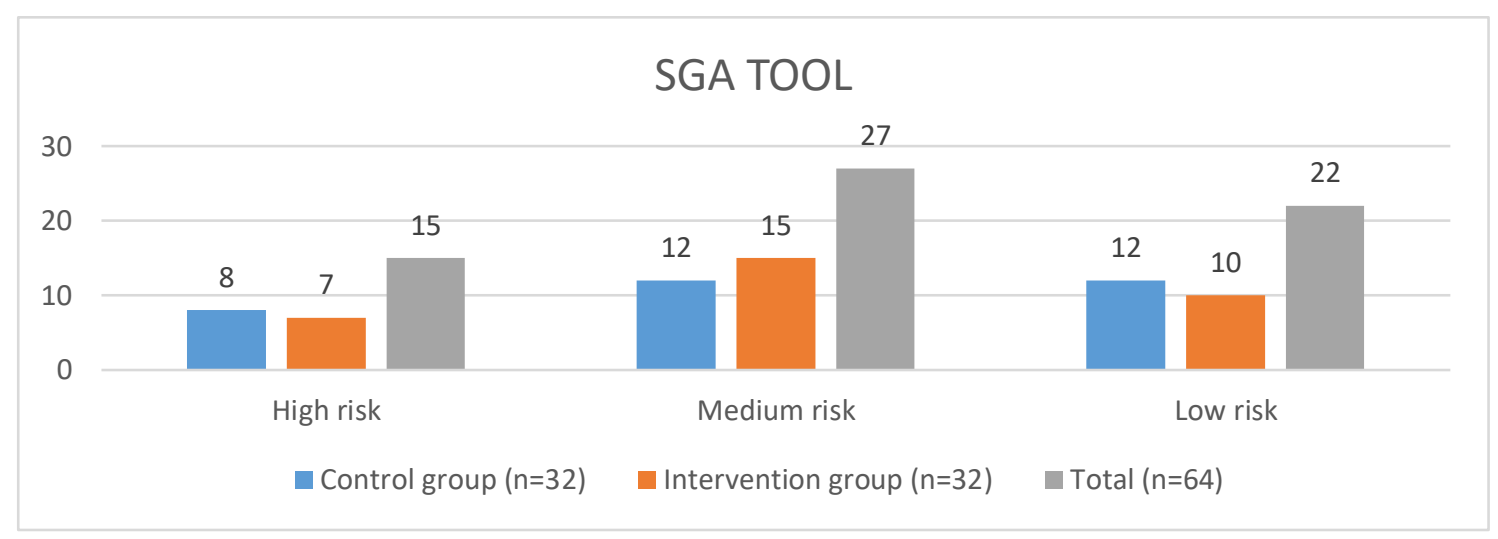

Figure 5. Subjective global assessment of orthopaedic patients $(n=64)$ 
Gastroenterology patients: MUST tool was used to assess the nutritional status of these patients. The malnutrition scores were calculated based on various criteria (BMI, weight loss, biochemical parameters, anthropometry parameters, and episodes of diarrhoea, vomiting, poor dietary intake and change in consistency of diet). Based on the number of episodes of gastrointestinal disturbances like diarrhoea and vomiting and its severity, the patients were then categorised into various groups of malnourishment. It was observed that $25 \%$ of the total patients were severely malnourished and $61.6 \%$ of patients were moderately malnourished (Figure 6).

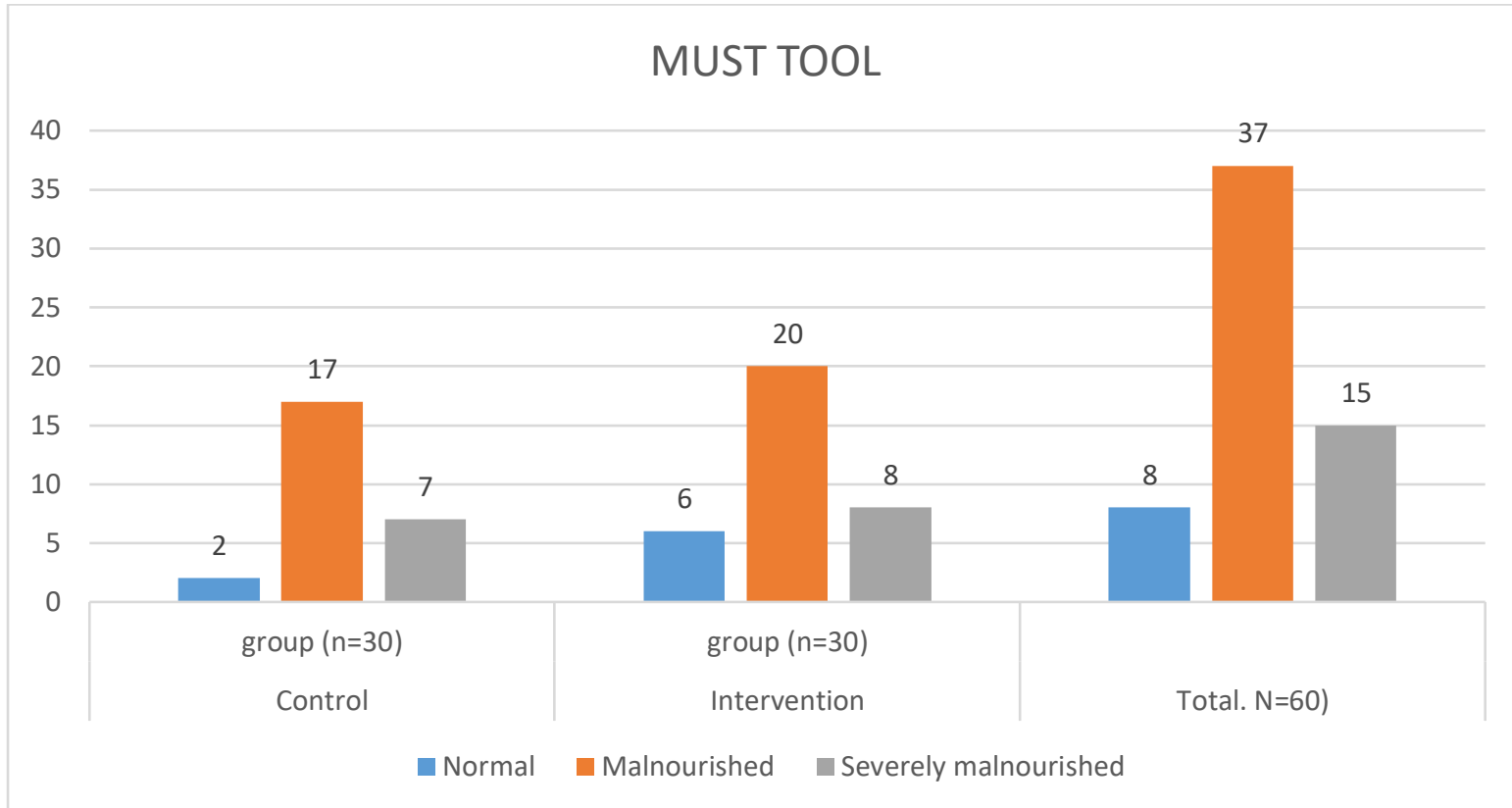

Figure 6. Nutritional statuses of gastroenterology patients $(n=60)$

\section{Data collection Post-surgery}

Biochemical parameters: It was observed that supplementation reduced the incidence of hypoglycaemia and prevented onset of thirst and hunger post-surgery which was indicated by the rise in random blood sugars in both in the orthopaedic intervention group $(128 \pm 12 \mathrm{mg} / \mathrm{dl})$ compared to control group $(122 \pm 10.5 \mathrm{mg} / \mathrm{dl})$ whose result were insignificant $(p>0.79)$ whereas gastroenterology intervention group patients had higher blood sugar levels(126 $\pm 18.5 \mathrm{mg} / \mathrm{dl})$ compared to control group $(115 \pm 10.2 \mathrm{mg} / \mathrm{dl})$ which was significant $(p<0.05)$ (Table 5). Also, there was a non-significant decline in platelet count in the intervention groups compared to control groups though both of which were in normal range. However, this reduction has led to reduction of blood thinner medications and lowered the risk to embolism in the intervention group.

Table 5. Platelet count and blood glucose level of Orthopaedic patients Post-surgery

\begin{tabular}{cccc|}
\hline Biochemical parameters & Control group $(\mathrm{n}=64)$ & Intervention group $(\mathrm{n}=64)$ & P value \\
\hline Platelets $\left(\times 10^{9}\right.$ per liter) & $176.85 \pm 46.5$ & $173.68 \pm 48.2$ & $\mathrm{P}=0.8$ \\
\hline $\begin{array}{c}\text { Random Blood sugar level } \\
\text { (mg/dl) }\end{array}$ & $122 \pm 10.5 \mathrm{mg} / \mathrm{dl}$ & $128 \pm 12 \mathrm{mg} / \mathrm{dl}$ & $\mathrm{p}>0.79$ \\
\hline
\end{tabular}


Table 6. Platelet count and blood glucose level of Gastroenterology patients Post-surgery

\begin{tabular}{|cccc|}
\hline Biochemical parameters & Control group $(n=60)$ & Intervention group $(n=60)$ & P value \\
\hline Platelets (x109per liter) & $325.53 \pm 93.75$ & $318.97 \pm 73.83$ & $P=0.8$ \\
\hline $\begin{array}{c}\text { Random Blood sugar level } \\
\text { (mg/dl) }\end{array}$ & $115 \pm 10.2 \mathrm{mg} / \mathrm{dl}$ & $126 \pm 18.5 \mathrm{mg} / \mathrm{dl}$ & $\mathrm{p}<0.05$ \\
\hline
\end{tabular}

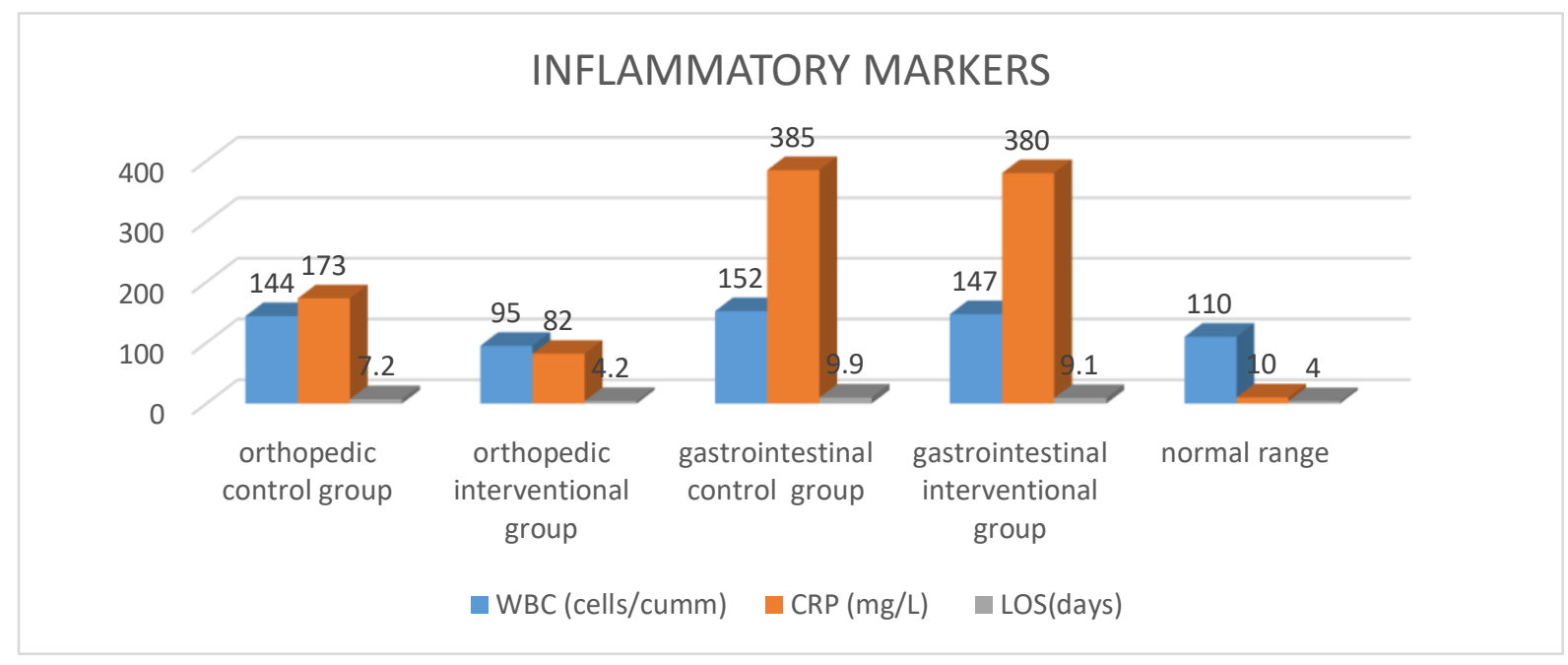

Figure 7. Post-surgery inflammatory markers of the participants

Orthopaedic patients: A significant negative correlation was seen between serum CRP, WBC and albumin levels pre surgery as mentioned above. The lower serum albumin level was associated with a significant rise in serum CRP levels $(P<0.0001)$ and WBC count $(p=0.05)$ in the control group (Table 7).

Table 7. Inflammatory markers of orthopaedic patients post-surgery $(n=64)$

\begin{tabular}{|llll|}
\hline & Control group $n=32$ & $\begin{array}{l}\text { Intervention group } \\
n=32 ; \text { Mean } \pm \text { SD }\end{array}$ & P value \\
\hline Parameters assessed & Mean \pm SD & $9525.5 \pm 32$ & $\mathrm{p}=0.053^{*}$ \\
\hline WBC(cells/cumm) & $14408 \pm 127$ & $82.82 \pm 44$ & $\mathrm{p}<0.0001^{*}$ \\
\hline CRP (mg/L) (Post & $173.03 \pm 59$ & & \\
\hline surgery only) & $7 \pm 2.4$ & $4 \pm 2.2$ & $\mathrm{p}=0.001^{*}$ \\
\hline LOS(days) & $3.4 \pm 0.5$ & $3.6 \pm 0.3$ & $\mathrm{p}<0.586$ \\
\hline Albumin(g/dl) & & & \\
\hline
\end{tabular}

*Significant at 0.05 level

Gastroenterology patients: In addition, the platelet count was lower in the intervention group indicating lower proneness to sepsis and embolism compared to control group (Table 6). It was observed that WBC count was higher post-surgery in both the control and intervention groups due to inflammation. The various micronutrients and phytochemicals present in the supplement might have contributed to the nonsignificant decline in the WBC count of intervention group compared to control group (Table 8). 
Table 8. WBC pre and post-surgery and LOS $(n=60)$

\begin{tabular}{|c|c|c|c|}
\hline WBC COUNT & GROUPs & Mean \pm SD & P value \\
\hline \multirow[t]{2}{*}{$\begin{array}{l}\text { WBC } \\
\text { pre surgery } \\
\text { (x109 perliter) }\end{array}$} & Control $(n=30)$ & $9988.57 \pm 3316.83$ & 0.9 \\
\hline & Intervention $(n=30)$ & $9952.63 \pm 2527.35$ & \\
\hline \multirow[t]{2}{*}{$\begin{array}{l}\text { WBC } \\
\text { Post-surgery day } 2 \\
\text { (x1099erliter) }\end{array}$} & Control $(n=30)$ & $\begin{array}{l}21550.40 \pm \\
6391.85\end{array}$ & 0.3 \\
\hline & Intervention $(n=30)$ & $\begin{array}{l}19942.63 \pm \\
2527.35\end{array}$ & \\
\hline \multirow[t]{2}{*}{$\begin{array}{l}\text { WBC } \\
\text { Post-surgery day } 4 \\
\text { (x109 perliter) }\end{array}$} & Control $(n=30)$ & $\begin{array}{l}15209.74 \pm \\
2836.34\end{array}$ & 0.5 \\
\hline & intervention(n=30) & $\begin{array}{l}14700.43 \\
\pm 2747.45\end{array}$ & \\
\hline \multirow[t]{2}{*}{$\begin{array}{l}\text { Length Of Hospital } \\
\text { Stay (Days) }\end{array}$} & control $(n=30)$ & $9.93 \pm 0.6$ & 0.3 \\
\hline & intervention $(n=30)$ & $9.13 \pm 0.3$ & \\
\hline
\end{tabular}

\section{B. Dietary energy and fluid Intake}

In the current study, pre surgery supplementation with GBR Nutritional mix was effective in increasing energy and fluid intake of both Orthopaedic ( $p>0.001)$ and Gastroenterology patients ( $p>0.05$ ) significantly (Figure $8)$.

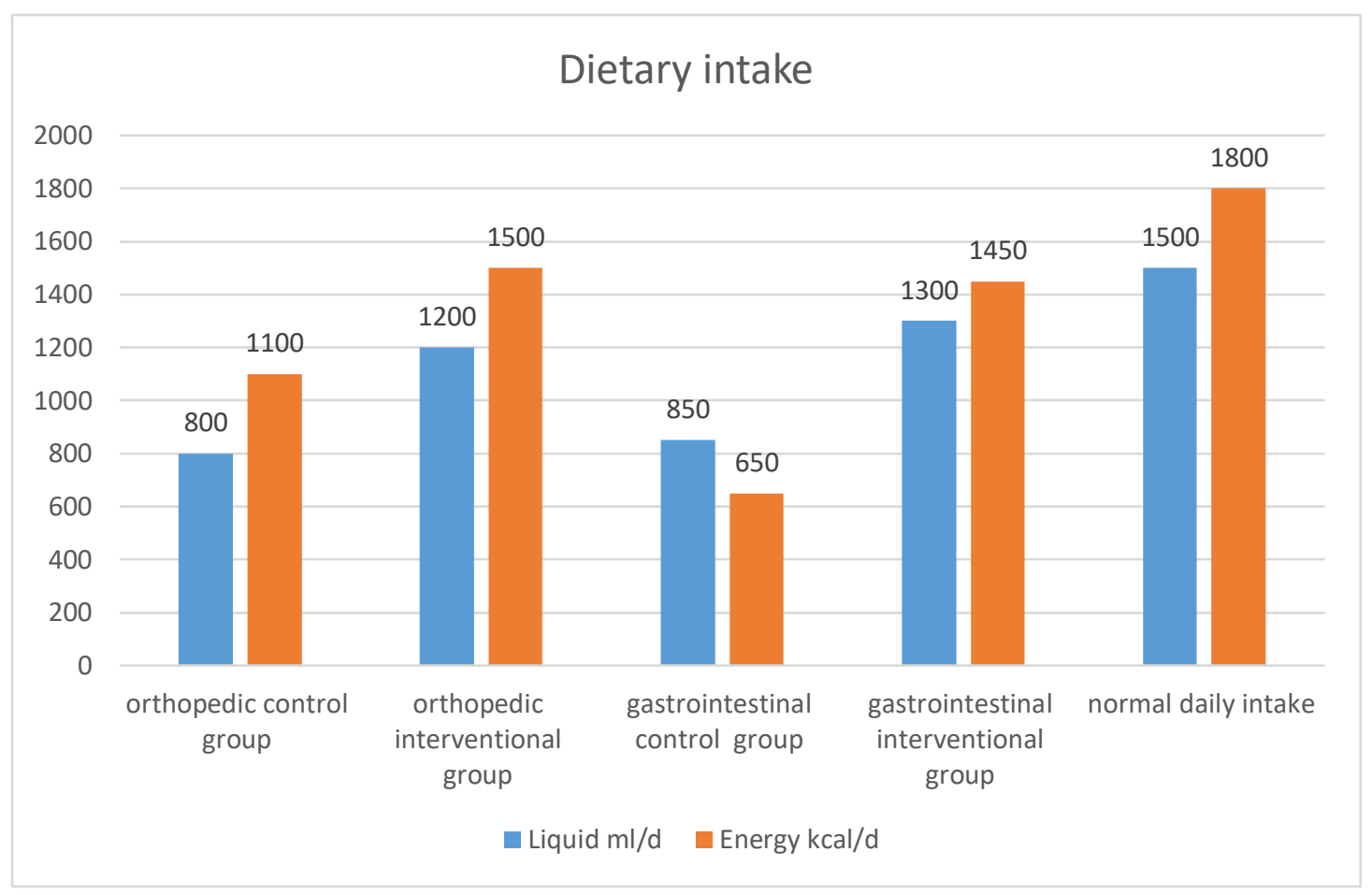

Figure 8. Food and energy intake of surgical patients post-surgery 


\section{DISCUSSION}

Malnutrition in gastrointestinal surgeries leads to poor quality of life and mortality at very early age [23]. Pausch et al (2012) studied 408 patients undergoing whipple's surgery and reported that patients with low BMI of $18 \mathrm{~kg} / \mathrm{m}^{2}$, experienced unintentional weight loss, cachexia and had longer hospital stay, higher complications and mortality within 90 days than patients with higher BMI of $30 \mathrm{~kg} / \mathrm{m}^{2}$ with many comorbidities [24].

Whereas study by Willhuber et al (2018) stated that malnutrition post orthopaedic surgery leads to various complications like anaemia, poor wound healing, post- surgery anxiety and poor appetite resulting in chromium deficiency, glucose intolerance, deep vein thrombosis, wound hematoma, urinary tract infection, constipation, pneumonia, excess pain post-surgery paralysis, electrolyte imbalance and atrial fibrillation, all of which affect an individual in the long-term. Surprisingly, this situation is more common in females. Hence pre-operative and post-operative care is very important [25].

In the present study it was observed that the number of female patients undergoing surgery was higher but, males and females both had poor nutritional status like anaemia and hypoalbuminemia prior to surgery. About $15 \%$ were at the high risk of malnutrition as assessed by Subjective global assessment tool (SGA) and Malnutrition Universal tool (MUST) (Figure 5 and 6). The intervention group of both gastroenterology and orthopaedic patients showed lower BMI of $15.8 \pm 4.25 \mathrm{~kg} / \mathrm{m}^{2}, 21 . \pm 3.32 \mathrm{~kg} / \mathrm{m}^{2}$ respectively along with lower MUAC, previous weight loss, poor haemoglobin and albumin status; and longer hospital stay (Figure-2 and 3). Cachexia was also observed both in females and males. Therefore, importance was given to the pre-operative nutrition which was rich in antioxidants.
A study by Sarah Rudasill et al (2018) on 3785 orthopaedic patients undergoing Total knee replacement and Total hip replacement surgeries recorded 114 (3\%) of patients with hypoalbuminemia that led to a significant increase in the cost of hospital stay $(p<0.001)$ and increased rate of readmission. It was concluded by the above authors that with every $1 \mathrm{~g} / \mathrm{dl}$ of increase in albumin, the LOS reduced and so the cost [26].

In the present study, the control group of orthopaedic patients had lower albumin level of $2.9 \pm 0.5 \mathrm{~g} / \mathrm{dl}$ compared to intervention group $3.2 \pm 0.2 \mathrm{~g} / \mathrm{dl}$ which might have resulted in their higher inflammation rate $(173.03 \pm 59 \mathrm{mg} / \mathrm{L}$ in control group and $82.82 \pm 44 \mathrm{mg} / \mathrm{L}$ in intervention group) and increased LOS. Also Hypoalbuminemia was observed in gastroenterology males (mean $2.3 \pm 2.4 \mathrm{~g} / \mathrm{dl}$ ) and females (mean $2.1 \pm 2.2 \mathrm{~g} / \mathrm{dl}$ ) and was corrected post-surgery using intravenous albumin on day 1.

Studies have also proven that changes in biochemical parameters in gastroenterology patients often lead to a drop in haemoglobin postoperative day1 and also some patients required blood transfusion of 1 liter (2 pint) preoperatively [27]. Similarly, in the present study $13 \%$ of males and $20 \%$ of females received blood transfusion. Moderate Leukocytosis was observed post-surgery but not correlated to complications (Table 8). Studies have stated that on the post-operative day 1 (POD1) there was a rise in WBC count which dropped gradually after a week. On the contrary, the chances of sepsis and infection increased when the WBC count raised [28]. Hence, it is important to keep a check on WBC count post-surgery. Higher levels were noted in orthopaedic and gastroenterology control groups (14408 \pm 127 cell/cumm ,15209.74 cells/cumm) as compared to intervention groups (9525.5 \pm 32 cell/cumm, 14700.43 cells/cumm) (Figure-7, Table 7 and 8). 
Impact of oral GBR nutritional supplement on postsurgery biochemical, clinical parameters and LOS: Study by Amer, M. A. et al (2016) stated that carbohydrate loading (45 gms) before elective orthopaedic surgery led to a significant reduction in the mean length of hospital stay of intervention group ( $4 \pm 2.2$ days) than control group ( $7 \pm 2.4$ days) $(p=0.001)$ [29] However, Arkley et.al (2019) stated that preoperative supplement with $400 \mathrm{kcal}$ and 20 gm protein in femoral neck surgery patients resulted in decline in readmission, complications and also had significant decline in LOS. It also stated that supplementation should be continued 3 days pre and 3 days post-surgery for better results [30].

A study by Kum Hee Son et al (2016) in 10 pancreatectomy cases proved that carbohydrate loading resulted in increased blood sugar and prevented insulin resistance which helped in early recovery and healing of surgical wounds. Hence it was recommended that hepatobiliary surgeries must surely consider carbohydrate loading pre surgery for better results [31] Similar results were observed in the intervention gastroenterology patients $(126 \pm 18.5 \mathrm{mg} / \mathrm{dl})$ of current study compared to control group $(115 \pm 10.2 \mathrm{mg} / \mathrm{dl}$ ) (Table $6)$.

It was also observed in the participants that the pre surgery supplementation was effective in increasing energy and protein intake of patients as the supplement contained maltodextrin (82.1\%) in combination with sucrose and protein from germinated brown rice all of which contributed to the total energy content of the recipe (Figure 8, Table 4). This is complementary to the study by Dwanna Ward-Boahen (2014) who stated that supplementation of combination of carbohydrate is absorbed faster by the gut lumen in pancreatectomy patients which is similarly suggested by ESPEN [32]. Moreover, the supplement developed in the present study is a source of Oryzanol, tocopherol and gamma amino butyric acid from brown rice that has been enriched with vitamins and zinc. Thereby when administered to intervention group the supplement helped in lowering WBC counts and CRP (inflammatory marker) post-surgery and reduced incidence of infection and length of hospital stay of the patients (Figure 7).

\section{CONCLUSION}

Supplementation of patients undergoing Gastrointestinal and orthopaedic surgeries with brown rice based nutritious product helped in reducing inflammation and complications, improved calorie intake pre and post-surgery and reduced length of hospital stay. Thus preoperative feeding with maltodextrin and micronutrient rich food would be therapeutically beneficial to orthopaedic and gastrointestinal patients.

Abbreviations: GBR: germinated brown rice, LOS: Length of hospital stay, HPLC: High performance liquid Chromatography, GABA: gamma aminobutyric acid, SGA: Subjective global assessment, MUST: Malnutrition universal assessment tool, MUAC: mid upper arm circumference, NBM: nil by mouth, WBC: white body cell, C-reactive protein WBC, TNF: Tumour necrosis factor, GLUT 4: Glucose transporter type, ESPEN: European society for clinical nutrition and metabolism, ASPEN: American society of parental and enteral nutrition CBC: Complete blood count, TPN: total parental nutrition, POD: post-operative day, BMI- body mass index.

\section{Authors' Contribution:}

Ms.P. Thacker - Development of GBR Nutritional mix and conducting the study, data collection, analysis and documentation; Dr.S. Mandalika Guided development of the GBR nutritional mix, study design, execution of the project and documentation. Dr. N. Doctor guided 
gastroenterology trial Dr. R. Shah - guided the orthopaedic trial

Competing Interest: Authors declare no conflict of interest

Acknowledgements: The investigators acknowledge Bhatia Hospital management for permitting us to carry out the study and all the participants for their cooperation and Piramal Neutraceuticals for developing vitamin mineral premix.

\section{REFERENCES}

1. Veenhof A.A.F. A, Sietses.C, Von Bloomerg B.M. E, VanHoogstrten I. W, V.D. Pas M.H.G.M. Meijerik, W.J.H. J, V. D Peet Tol MP, Bonjer H. J, Cuesta A: The surgical stress response and postoperative immune function after laparoscopic or conventional total mesorectal excision in rectal cancer: a randomized trial. Int J Color Dis 2011, 26:53-59. https://doi.org/10.1007/s00384-010-1056-9

2. Ljugqvist $\mathrm{O}$, Nygre NJ, Thorell: A Modulation of post operative insulin resistance by preoperative carbohydrate loading. Proc. Nutr. Soc. 2002, 61:329-336. DOI: $10.1079 /$ PNS2002168

3. Ljungqvist $\mathrm{O}$ : Insulin resistance and outcomes in surgery. J Clin Endocrinol Metab. 2010, 95: 42174219. https://doi.org/10.1210/jc.2010-1525

4. Sato $H$, Carvalho $G$, Sato $T$, Lattermann R, Matsukawa $T$, Schricker T: The association of preoperative glycemic control, intraoperative insulin sensitivity, and outcomes after cardiac surgery. J Clin Endocrinol Metab.2010, 95: 4338-4344. https://doi.org/10.1210/jc.2010-0135

5. Rubinson L, Diette GB, Song X, Brower RG, Krishnan JA: Low caloric intake is associated with nosocomial bloodstream infections in patients in the medical intensive care unit. Crit Care Med. 2004, 32:350-357.

DOI: 10.1097/01.CCM.0000089641.06306.68

6. Villet S, Chiolero R, Bollmann M, Revelly J, Cayeux M, Delarue J, et al: Negative impact of hypocaloric feeding and energy balance on clinical outcome in ICU patients. Clin. Nutr. 2005,24(4):502-509. DOI: 10.1016/j.clnu.2005.03.006

7. Pappas S, Krzywda E, McDowell N: Nutrition and Pancreaticoduodenectomy. Nutrition in Clinical Practice 2015, 30 : 162-162 doi.org/10.1177/0884533610368709

8. Gupta D, Vashi PG, Lammersfeld CA, Braun DP: Role of nutritional status in predicting the length of stay in cancer: a systematic review of the epidemiological literature. Ann NutrMetab 2011, $59 \quad$ : 106.https://doi.org/10.1016/j.clnu.2013.06.016

9. Noblett SE, Watson DS, Huong H, Davidson, Hainsworth PJ, Horgan AF: Preoperative oral carbohydrate loading in colorectal surgery: A randomized controlled trial. $\begin{array}{llll}\text { Colorectal } & \text { Dis } & \text { 2006; } & 8: 563\end{array}$ https://doi.org/10.1111/j.1463-1318.2006.00965.x

10. Harsten et al: Total hip arthroplasty and preoperative oral carbohydrate treatment; a randomized double blind controlled trial. Euro. J. of Anesthesio. 2012, 29: 271-4. DOI: 10.1097/EJA.0b013e3283525ba9

11. Lauwick et al: Effect of oral preoperative carbohydrate on early postoperative outcome after thyroidectomy. Acta. Anesthesiologica Belgica. 2009, 60 (2):67-73. PMID: 19594087

12. Zhao et al: Effect of fast track surgery on insulin resistance indexes of oesophageal cancer patients. Supportive Care in Cancer 2013, 21: S22 doi: 10.1007/s00520-013-1979-0.

13. Moppett, I.K., Greenhaff, P.L., Ollivere, B.J. et al: PreOperative Nutrition in Neck of femur Trial (POINT) carbohydrate loading in patients with fragility hip fracture: study protocol for a randomised controlled trial. Trials 2014, 15: 475. https://doi.org/10.1186/1745-6215-15-475

14. Gagheggi Ravanini, Pedro Eder Portari Filho, Renato Abrantes Luna and Vinicius Almeida de Oliveira: Organic inflammatory response to reduced preoperative fasting time, with a carbohydrate and protein enriched solution; a randomized trial. Nutr Hosp. 2015, 32(2):957-957 DOI: 10.3305/nh.2015.32.2.8944

15. Paula Alves Pexe-Machado, Benedito Dario de Oliveira: Shrinking pre-operative fasting time with maltodextrin and protein hydrolysate in gastrointestinal resections due to cancer. Nutrition 2013, doi:10.1016/j.nut.2013.02.003

16. Wu, F., Yang, N., Touré, A., Jin, Z., and Xu, X.: Germinated brown rice and its role in human health. Critical reviews in food science and nutrition 2013, 53(5): 451-463. https://doi.org/10.1080/10408398.2010.542259

17. Mustapha Umar Imam, Siti Nor Asma Musa and Maznah Ismail: Effects of White Rice, Brown Rice and Germinated Brown Rice on Antioxidant Status of Type 2 Diabetic Rat. Int J Mol Sci. 2012, 13(10): 12952- 12969. DOI: $10.3390 /$ ijms131012952

18. Kazemzadeh, Safavi, Nematollahi S, Nourish Z: Effect of Brown Rice Consumption on Inflammatory Marker and Cardiovascular Risk Factors among Overweight and Obese Non-Menopausal Female Adults. Int J Prev Med.2014, April 5(4):478-488. PMCID: PMC4018597 
19. ThitimaKaosa- ard and SirichaiSongermpong: Influence of germination time on GABA content and physical properties of germinated brown rice. Asian Journal of Food Agro Industry 2012, 5(504):270-283

20. Watanabe S, Hirakawa A, Nishijima C, et al: Food as medicine: The new concept of "medical rice". Adv Food Technol Nutr Sci. Open J. 2016, 2(2): 38-50. doi: 10.17140/AFTNSOJ- 2-129

21. Swati Bhauso Patil and Md. Khalid Khan: Germinated brown rice as a value added rice product: A review. J. Food Sci. Technol. 2012, 48(6): 661-667. doi: 10.1007/s13197011-0232-4 PMCID: PMC3551059

22. Neumaier $M$ etal: Review Article-Reactive Protein in Orthopaedic Surgery. Acta. Chir. Orthop. Traumatol Cech 2015, 230-235

23. Prashanth Rawla, Tagore Sunkara, and Vinaya Gaduputi: Epidemiology of Pancreatic Cancer: Global Trends, Etiology and Risk Factors. World J Oncol. 2019 Feb, 10(1): 10-27. doi: 10.14740/wjon1166PMCID: PMC6396775 PMID: 30834048

24. Pausch T, Hartwig W, Hinz U, et al: Cachexia but not obesity worsens the postoperative outcome after pancreatoduodenectomy in pancreatic cancer. Surgery. 2012, 152(3 Suppl 1): S81-S88. https://doi.org/10.1016/j.surg.2012.05.028

25. Willhuber, G. C., Stagnaro, J., Petracchi, M., Donndorff, A., Monzon, D. G., Bonorino, J. A., Zamboni, D. T., Bilbao, F., Albergo, J., Piuzzi, N. S. and Bongiovanni, S: Short-term complication rate following orthopedic surgery in a tertiary care center in Argentina. SICOT-J, 2018, 4: 26. https://doi.org/10.1051/sicotj/2018027

26. Rudasill, S. E., Ng, A., and Kamath, A. F: Preoperative Serum Albumin Levels Predict Treatment Cost in Total Hip and Knee Arthroplasty. Clinic. in orthopaedic surgery, 2018, 10(4):398-406. https://doi.org/10.4055/cios.2018.10.4.39

27. McBride KA, Ballinger ML. Li: Fraumeni syndrome: cancer risk assessment and clinical management. Nat Rev Clin Oncol. 2014, 11(5):260-271. DOI: 10.1158/10780432.CCR-17-0408.

28. SucB, Panis Y, Belghiti J.Fekete F: Natural history of hepatectomy. $\mathrm{Br} J \quad$ Surg. 1992, 79:39-42. DOI: $10.1002 /$ bjs. 1800790113

29. Amer, M. A., Smith, M. D., Herbison, G. P., Plank, L. D., and McCall, J. L: Network meta-analysis of the effect of preoperative carbohydrate loading on recovery after elective surgery. The British journal of surgery 2017, 104(3):187-197. https://doi.org/10.1002/bjs.10408

30. Arkley, J., Dixon, J., Wilson, F., Charlton, K., Ollivere, B. J., and Eardley, Assessment of Nutrition and Supplementation in Patients with Hip Fractures. Geriatric orthopaedic surgery and rehabilitation, 2019; 10, 2151459319879804. https://doi.org/10.1177/2151459319879804

31. Son, K. H., Kim, S. Y., Cho, Y. A., Wie, G. A., Han, S. S., and Park, S. Preoperative Oral Carbohydrate Loading in Pancreaticoduodenectomy. Clinical nutrition research, 2016;5(3),213-218. https://doi.org/10.7762/cnr.2016.5.3.213

32. Dwanna Ward-Boahen and Meredith Wallace-Kazer: Improving Surgical Outcomes in Pancreatic Surgery with Preoperative Nutrition. Adv Pract Oncol. 2014,5(2): 100106,DOI: 10.6004/jadpro.2014.5.2.4.PMCID:_PMC4093512 .PMID: 25032044 